\title{
The Declining Utility of Analyzing Burdens of Persuasion
}

\author{
Ronald J. Allen ${ }^{*}$
}

\section{FESTSCHRIFT FOR MICHAEL RISINGER}

The title of this panel is "The Weight of Burdens: Decision Thresholds and how to get ordinary people to operationalize them the way we want them to." I am a somewhat odd choice to be answering that question, since, apart from a few aberrational efforts during my misbegotten youth ${ }^{1}$ when I was not thinking clearly about the distinction between normative and positive work, my research program is as positive as I can make it. The closest to this title that an aspect of my research program attempts to shed light on is the question of the nature of juridical proof rather than what it should be or how do we get jurors to act in one way or another. To be sure, once one has a confident grasp of the answer to that question, normative proselytizing can begin, by those who wish to do it, either to enhance or modify the structure in place - but that is not a serious motivation of my work. I cheerily assume that, generally speaking (a point soon to be developed further), fact finders (judges are no different from jurors) do exactly what we ask them to do, which is to determine to their best ability what actually happened concerning a litigated event, and apply the law as they understand it to the facts that are found. ${ }^{2}$ For me, one of the interesting questions is the extent to which the

\footnotetext{
* John Henry Wigmore Professor of Law, Northwestern University Pritzker School of Law; President, International Association of Evidence and Forensic Science; Fellow, The Forensic Science Institute, China University of Political Science and Law.

1 References provided on request.

2 This cheery assumption received considerable vindication from the Arizona Jury Project. The authors summarize the empirical data:
}

\begin{abstract}
The conventional wisdom on jury comprehension of legal instructions is only partially correct: juries do struggle with jury instructions, and they sometimes misapply legal rules in reaching their verdicts. With some important exceptions, however, the deliberations of the Arizona jurors as they discussed legal issues were remarkably consistent with the instructions they received. Moreover, the evidence presented here shows that deliberations do assist in resolving individual misunderstandings. The jurors in Arizona, armed with individual copies of the jury instructions, were able to correct nearly half of the errors made during their deliberations.
\end{abstract}


American legal system facilitates or retards that effort, and with what costs and benefits, rather than how we get "them" to do what we want them to do. That question leads in turn to my major research program on the nature of juridical proof. $^{3}$

In analyzing the question of the nature of juridical proof, the evidence literature spends an inordinate amount of effort on burdens of proof and the so-called proof paradoxes such as the conjunction effect. I bear some responsibility for this, having once also looked at the problem through that lens. ${ }^{4}$ Although that early literature was interesting and helpful in many respects, in my opinion the fascination with the proof paradoxes, and thus the burden of proof, has become unproductive. It continues to generate what Kevin Clermont refers to as "contortions," prime example, in order to explain away something that cannot be explained away. The conjunction effect is a feature of the world; it is not a feature of our explanation of the world. If more than one conclusion needs to be reached to decide some issue (whatever it is), and if a false positive on any would render a mistaken decision, then errors will accumulate as a function of errors on those discrete conclusions. Simple as that. One can pretend this does not exist and/or its consequences are trivial, ${ }^{6}$ accept it and move on, ${ }^{7}$ or wish it away apparently from the belief that changing one's views of probability will change the external world. ${ }^{8}$ But, whatever you do, it is not going away.

Shari Seidman Diamond, Beth Murphy \& Mary R. Rose, The “Kettleful Of Law” In Real Jury Deliberations: Successes, Failures, And Next Steps, 106 Nw. U. L. Rev. 1537, 1605 (2012). Moreover, some of the "errors" were actually deliberate forms of jury nullification, which the authors call "resistance errors." Id. at 1601.

3 See, e.g., Ronald J. Allen, The Nature of Juridical Proof, 13 CARDOzo L. REv. 373, 373-422 (1991); Ronald J. Allen, The Nature of Juridical Proof: Probability as a Tool in Plausible Reasoning, 21 InT'L J. EvidenCE \& ProOF 133, 133-42 (2017).

4 Of the many sources of evidence for this sin, see Ronald J. Allen, $A$ Reconceptualization of Civil Trials, 66 B.U. L. REV. 401, 401-37 (1986).

5 Kevin M. Clermont, Common Sense on Standards of Proof (Cornell Legal Studies Research Paper No. 17-37, 2017), https://ssrn.com/abstract=3007129. Ronald J. Allen \& Michael S. Pardo, Relative Plausibility and Its Critics, InT'L J. EvidenCE \& ProOF (forthcoming 2019) (providing a thorough discussion of this and other competitors of the relative plausibility theory).

6 See David S. Schwartz \& Elliott Sober, The Conjunctions Problem and the Logic of Jury Findings, 59 WM. \& MARY L. REV. 619 (2017).

7 See Dale A. Nance, The Burdens of Proof: Discriminatory Power, Weight of Evidence, AND TENACITY OF Belief (2016); Mark Spottswood, Unraveling the Conjunction Paradox, 15 LAW, Probability \& RisK 259 (2016).

8 See Kevin M. Clermont, Standards of Decision in Law: Psychological and Logical Bases for the Standard of Proof, Here ANd Abroad (2013). 
One reason for the continued fascination with burdens of proof is the belief that the conjunction effect is the biggest obstacle to a robust probabilistic interpretation of juridical proof, and again I bear some responsibility for this, for which I would like to publicly apologize after all these years. ${ }^{9}$ The proof paradoxes were the grains of sand in the oyster that stimulated thought, to mix metaphors, but they were never the heart of the problem for precisely the reason just mentioned: features of the world will not be changed by changing our mental apparatus. The significance of the proof paradoxes, in my opinion, lies solely in their opening up skepticism about whether a potentially powerful account of juridical proof with a probabilistic foundation was justifiable. It turns out it was not, but again not just because of this feature of the world. Any explanation of juridical proof must give an account of this aspect of the world to have any chance of success.

Rather, the deeper problem is that no interpretation of probability makes much sense in the context of litigation. Much of the literature just ignores this point, which makes that part of the literature completely uninteresting. ${ }^{10}$ Those who recognize the deep problem here branched into two directions, one explaining proof at trial as involving plausible reasoning (of which probability is a part) ${ }^{11}$ and the other embracing some form of subjective probability. ${ }^{12}$ The difficulty with the subjective probability move is that it is indeed subjective. Subjective probability was not designed for and cannot easily accommodate truth conducive procedures; it was designed to elicit personal views and to maintain consistency among them. It is true that if subjective views are systematically updated with data in the form of objective likelihoods, there are reasons to believe that the final conclusions of different decision makers will converge, and occasionally converge on the

9 It all started in 1986. See Allen, supra note 4; see also Ronald J. Allen, Factual Ambiguity and a Theory of Evidence, 88 Nw. U. L. REV. 604, 604 (1994) (arguing that the "most damaging" proof paradox tending to undermine "the conventional [probabilistic] view" of burdens of proof is "the remarkable consequences of the conjunctive effect implicit in the conventional theory").

10 Reading other people's work, I have often thought that the authors of sentences like the one to which this footnote is attached should be required to give references, but at the moment I am happy to be relieved of such an obligation.

11 See, e.g., Ronald J. Allen \& Alex Stein, Evidence, Probability, and the Burden of Proof, 55 ARIZ. L. ReV. 557 (2013); Michael S. Pardo \& Ronald J. Allen, Juridical Proof and the Best Explanation, 27 LAW \& PHIL. 223, 223-68 (2008).

12 Clermont, supra note 8; NANCE, supra note 7. An astonishing example of this is Kenneth S. Broun et AL., McCormick On Evidence 483 (John W. Strong et al. eds., 6th ed. 2006), where the authors claim that certain instructions are misleading because they "divert attention to the evidence," whereas they should focus on the degree of the juror's belief. As Susan Haack pithily put it, "this has things exactly backwards." SUSAN HAACK, EVIDENCE MATters: SCIENCE, PROOF, AND TRUTH IN THE LAW 52 (2014). 
truth $;^{13}$ but objective data in this form is precisely what virtually never exists at trial and is the original cause of the failure of probabilistic explanations (supplemented with computational intractability, which again while true is not the central problem).

This is what led scholars to explore other explanations, and as Clermont points out, the most durable of these has been relative plausibility. ${ }^{14}$ But relative plausibility is not simply an explanation of the burden of persuasion instructions; it is an explanation that encompasses the entire proof process. The American legal system, generally speaking: (1) encourages the presentation of competing explanations of the relevant events; (2) in civil cases, makes the evidence necessary to support those explanations available (and to some extent also in criminal cases); (3) provides liberal rules of admission to allow the parties to tailor their cases to their best advantage; and (4) encourages articulations by both parties of the theory of the case in pleadings, discovery, opening statements, and closing arguments. Lawyers regularly describe their activity as showing that "their version of the case" is what happened, ${ }^{15}$ and courts routinely point out the obvious - that the "probability" of something happening depends on the alternatives. ${ }^{16}$

This last point deserves some elaboration. The central idea of relative plausibility is that fact finders employ their full panoply of cognitive tools, assisted by the parties, to judge which explanation or combination of explanations is the most plausible, and by doing so, to determine the most likely explanations of events. So, at the end of the day, relative plausibility incorporates elements of probability explanations; errors are kept under control and allocated appropriately by deciding for the most plausible explanation or set of explanations in civil cases and deciding whether there are plausible stories of guilt and innocence in criminal cases. The point, however, is that the judgment of plausibility is done using conventional cognitive tools such as appraisals of consistency, coverage, etc., and as I will

13 Allen, supra note 3; Ronald J. Allen, Rationality, Algorithms and Juridical Proof: A Preliminary Inquiry, 1 INT’L J. EvidenCE \& PROOF (SPECIAL IsSUE) 254 (1997).

14 See CleRmont, supra note 8.

15 A useful collection of such descriptions is the NAT'L ASSOC. OF CRIMINAL DEF. LAWyers, POWERful Words: StORYTElling \& PERSUASION TeChNiQues FOR COMMUNICATING YOUR THEORY OF THE DEFENSE (2016). Virtually never is the "theory of the defense" that a discrete element is false. It is rather that the defense "story" is inconsistent with guilt.

16 See, e.g., Anderson v. Griffin, 397 F.3d 515, 521 (7th Cir. 2005); United States v. Beard 354 F.3d 691, 693 (7th Cir. 2004). In criminal cases, the issue is whether there is a plausible story of guilt and no plausible story of innocence. See, e.g., United States v. Newell, 239 F.3d 917, 920 (7th Cir. 2001). The Supreme Court acknowledged the relative nature of proof in City of Los Angeles v. Alameda Books, Inc., 535 U.S. 425, 437-38 (2002) (finding that the City justified its statute restricting adult businesses, the Court said: "Neither the Court of Appeals, nor respondents, nor the dissent provides any reason to question the city's theory. In particular, they do not offer a competing theory"). 
turn to in a moment, Michael Risinger's interesting suggestion of surprisebut none of this can be done unless there are alternatives. And the alternative in American litigation virtually never is that the plaintiff's explanation is false. Rather, the alternative is that the defendant's explanation is true, and thus the plaintiff's explanation is false. Analytically this need not be truea point that Clermont exploits ${ }^{17}$ — but practically it is. Otherwise, plaintiffs would have to show half plus one of the ways the world could have been favor liability, or criminal defendants could defend successfully by bringing in the phone book or some other weird "contortion."18 Observation shows those are not the world we actually live in.

A few counter-examples can be given to the relative plausibility explanation. Surely once in a while a defendant does little more than attempt to negate an element (and I predict they almost always lose), and occasionally there is substantial relative frequency data that permits probabilistic explanations to dominate. But one should not ask too much of an explanation or theory in this context. Both the legal system generally and the litigation process specifically are not top-down made systems explainable by simple propositions emanating from their creators. Rather, they are bottom-up grown systems. To use an image I frequently invoke, they are more like rain forests than tree farms. They are complex adaptive systems, rather than simple static systems. ${ }^{19}$ There will always be counterexamples to any explanation of such systems. Thus, the important question is not whether any particular theory suffers from no counter-examples, but instead the extent to which it advances understanding. On that score, all the recent writings on burdens of proof have their merits, although none of them has the explanatory force or scope of relative plausibility, in my humble opinion.

Ironically, given the fascination with the conjunction effect and relative plausibility, the present instructions, which obviously focus the fact finder's attention on each element, ${ }^{20}$ are at least superficially as much of a problem

17 This is what motivates his discussion of, and reliance on, belief functions. CLERMONT, supra note 8 , at 201 .

18 Clermont tries to avoid this by suggesting that there is an unallocated belief between $\mathrm{X}$ and not-X, but he completely ignores where any belief in not-X comes from. I suggest it typically comes from the defendant who provides evidence of $Y$, which entails not-X.

19 Ronald J. Allen, Rationality and the Taming of Complexity, 62 ALA. L. REV. 1047 (2011)

20 This was systematically established in Ronald J. Allen \& Sarah A. Jehl, Burdens of Persuasion in Civil Cases: Algorithms v. Explanations, 4 Mich. St. L. Rev. 893 (2003). Professor Nance remains unconvinced, and recently reiterated that a number of pattern jury instructions are "consistent" with requiring findings of the conjunction of the elements. NANCE, supra note 7, at 76-77. Michael S. Pardo and I in a forthcoming article, Relative Plausibility and Its Critics, systematically dismantle these types of assertions. Just as one of many examples, when one looks at the actual instructions given in pertinent cases, one finds 
for relative plausibility as any of these other attempts to explain juridical proof (I explain its resolution at the end of this essay). That is why the analysis moved beyond them to embed them in their larger context. They are, as it were, the odd man out. There is simply an unavoidable tension between looking at elements discretely, if the question is the truth OR NOT of some element, and any sensible approach to burdens of persuasion. Thus I tend to agree with Professor Dale A. Nance's view that they express necessary but not sufficient conditions. ${ }^{21}$ What is sufficient, however, is not the conjunction of the elements. That, too, suffers from debilitating problems. Without knowing what the alternatives are, one cannot assign probability or anything else to an explanation except to say that it is plausible (or not) given the evidence. And one can say that only because no alternative has been produced; there is thus one explanation backed by evidence, which must be the case, so far as anyone can tell, in the absence of any other. One has to know what it is competing with, as the legal system recognizes over and over again, in order to know who wins. If there is no competition, the one explanation standing, whether in civil or criminal cases, wins.

Consequently, it is not quite accurate to assert that the relative plausibility theory "contort[s itself] in efforts to find ways to live with the law's approach." 22 Instead, it points out how the American legal system evolved a means of controlling its consequences. Rather than have fact finders focus on the elements OR NOT of a plaintiff's case, regardless of what the instruction on the burden of persuasion actually says, the American legal system encourages the presentation of alternative explanations, ${ }^{23}$ which

cases like In re Corrugated Container Antitrust Litigation, in which the Court of Appeals approved jury instructions and a special verdict form that had the effect of adopting the plaintiff's requested instruction that: "If you find that the plaintiffs have established these two elements by a preponderance of the evidence, then your verdict must be for the plaintiffs. If the plaintiffs have not established both elements, then your verdict must be for the defendants." In re Corrugated Container Antitrust Litig., 756 F.2d 411, 416 (5th Cir. 1985). The disagreement in the case was over the substantive law, not over whether findings of each element was sufficient for a verdict. Id.

21 See, e.g., supra note 7, at 73074.

22 Clermont, supra note 5 , at 2.

23 For some reason, the critics of the relative plausibility theory assert that it is committed to the story model of jury decision-making propounded by Pennington and Hastie. See Clermont, supra note 5. This is a peculiar assertion. The work of Pennington and Hastie certainly supplies some empirical support for the relative plausibility explanation, as does the more important work of the Arizona Jury Project which finds that jurors attempt to construct the most plausible account of the litigated events. See, e.g., Diamond, Murphy \& Rose, supra note 2 , at 1575 . "They actively search for ways to make sense of events about which they are told, consciously or unconsciously filling in blanks and resolving ambiguities to produce a plausible account and arrive at what they understand to be a just verdict consistent with the evidence and instructions." Id. But explanations can come in many different forms. If a party chooses to provide something other than a coherent chronological narrative, there is nothing that stops it from doing so, and nothing inconsistent in doing so with the relative 
distributes the logical problems over both sides of the dispute. This has been known for a long time. ${ }^{24}$ A more recent addendum to the explanation of juridical proof is the recognition of the massive overlapping of evidence that tends to occur at trial. Most of what plaintiffs (including the state in criminal cases) and defendants assert is quite consistent, with the parties choosing to dispute only parts of the overall explanations. ${ }^{25}$ As the range of the dispute narrows, the logical problems diminish as well.

Professor Risinger now adds to the literature a novel exegesis on burdens of persuasion that focuses on the surprise that a fact finder would feel if he or she learned that a mistake had been made. ${ }^{26}$ As with all of Professor Risinger's writings, this is both insightful and provocative. It is also his first foray into this particular territory, so far as I know, and not surprisingly the proposal is somewhat underdeveloped. I thus commend its creativity and offer a few suggestions. ${ }^{27}$ First, although Professor Risinger wisely eschews conventional probability theory as a main component in his proposal, nonetheless at this stage in development it appears to bear some relationship to the proposals of the original creators of formalized subjective probability. It is basically an algorithm for determining the extent of one's commitments to certain propositions or drawing out one's utility functions and preferences. Leonard J. Savage, Bruno De Finetti, and others asked

plausibility theory. Whatever explanation is offered will be considered in light of its alternatives. For a discussion of the differences between the story model and explanations, see Michael S. Pardo, The Nature and Purpose of Evidence Theory, 66 VAND. L. REV. 547, 598-99 (2013).

Critics also consistently assert that the relative plausibility theory cannot accommodate intermediate standards of proof, such as clear and convincing evidence. NANCE, supra note 7, at $82 \mathrm{n} .219$. This is an equally peculiar assertion. It is equivalent to saying that human decision-making does not encompass the view that some explanations are much more plausible than others, or equivalently that without the apparatus of probability theory statements such as "I think it is much more likely to rain tomorrow than be sunny," are meaningless. Such statements lack the false precision of a probability statement, but they are perfectly comprehensible. Indeed, one of the ironies of the probability debates is that critics, such as Professor Nance, who make such points never define what "clear and convincing" evidence is within their framework. Or beyond reasonable doubt, either. Again, the relative plausibility theory handles things naturally, or as Professor Clermont might say, with good common sense.

24 Allen, supra note 4 , at 426.

25 Pardo, supra note 23, at 576-87.

26 Michael D. Risinger, Leveraging Surprise: What Standards of Proof Imply that We Want from Jurors, and What We Should Say to Them to Get It, 48 SETON HALl L. REV. 965 (2018).

27 My frequent co-author, Michael S. Pardo, provides a philosophically rich and interesting discussion of Risinger's proposal and its relationship to relative plausibility, and so I content myself here with a few gap filling comments. Michael S. Pardo, Epistemology, Psychology, and Standards of Proof: An Essay on Risinger's "Surprise” Theory, 48 SETON HALL L. REV. 1039 (2018). 
different questions but they were put to similar purposes. ${ }^{28}$ The difference between the subjectivists and Shackle to some extent lies in the definiteness with which an answer must be given, but it is not clear to me how much of a difference that difference makes in the juridical context. Asking people if they would be really surprised sounds similar to asking them if they would make a really big bet on the truth of some proposition. One loses much of the ability to compute easily without cardinal answers, but you get the same basic output. Or so it seems to me at the moment. I look forward to further explication from Professor Risinger.

The second point is perhaps more fundamental, and it is one that Professor Risinger alludes to but does not develop, and that is the ambiguous relationship between ex ante and ex post analysis. Ex ante, the question fact finders face is whether a burden of persuasion has been satisfied, however that is accomplished. In asking fact finders how surprised they would be to find out they were wrong, what ex post counter-factual worlds may be considered? Whether some new evidence might appear? Whether some probative evidence was excluded? Whether witnesses lied? Whether the government planted inculpatory evidence? Whether the defendant murdered a potentially important witness? I suspect, ex post, I would be very surprised by some outcomes, but not others. How the surprise theory handles such matters needs to be developed.

The nature of the case matters as well. Suppose I am a juror in a criminal case and conclude (using relative plausibility) that there is a plausible case of guilt and none of innocence, although another juror thinks to the contrary. Whatever the outcome of the case (however the initial disagreement was resolved), how surprised would I be that another reasonable person's view of the evidence turned out to be a better appraisal of the situation than mine? Not very, I would think, for these are ambiguous problems. Map this onto Professor Risinger's proposal directly. Before deliberation, my view is that I would be very surprised if the defendant were innocent, and yours is that you would be very surprised that the defendant is

28 From Alan HájeK, The Stanford EnCyClopedia of Philosophy: InTERPRETATions of ProbabiLity (Edward N. Zalta ed., 2002), https://plato.stanford.edu/entries/probabilityinterpret/\#SubPro:

Utilities (desirabilities) of outcomes, their probabilities, and rational preferences are all intimately linked. The Port Royal Logic (Arnauld, 1662) showed how utilities and probabilities together determine rational preferences; de Finetti's betting analysis derives probabilities from utilities and rational preferences; von Neumann and Morgenstern (1944) derive utilities from probabilities and rational preferences. And most remarkably, Ramsey (1926) (and later, Savage 1954 and Jeffrey 1966) derives both probabilities and utilities from rational preferences alone. 
guilty. Having deliberated on those views, I would not be very surprised at all if your view instead of mine were true, again because a reasonable person considering the same evidence as I did reached a different conclusion. How does the surprise theory handle this?

I encourage Professor Risinger to go more deeply into this interesting theory. Like all good ideas first propounded, Professor Risinger's is provocative but not necessarily complete, and I raise these points as hopefully helpful suggestions for developing it further. I should also emphasize that Professor Risinger is not attempting to explain juridical proof, but, I believe, to improve on what he sees. Part of the future development of the idea should include reasons to think fact finders would do better than they presently do by having this structure imposed upon them.

Of the two recent major analyses of burdens of proof, I focus here on Professor Clermont's analysis. ${ }^{29}$ Unlike Professor Risinger, Professor Clermont is quite sure that he has a better explanation than any of those that have been advanced to date about the nature of juridical proof, and Professor Nance is somewhat unclear whether he is focusing on explication or reform. ${ }^{30}$ By contrast, Professor Clermont is plainly working the same field that I am, and I appreciate his acknowledgement that my work is the "hardiest contortion" 31 of the various corpuses on offer other than his. Were my Mother here to guide me, she would tell me to accept the compliment, such as it is, sit down, and shut up. Using Professor Risinger's approach, she would not be surprised at my disregarding her sage advice.

My view of the lay of the land is, not surprisingly, somewhat different from Professor Clermont's. Professor Clermont has produced a marvelous work of scholarship reflecting great, indeed astonishing erudition. ${ }^{32}$ I think he is plainly correct in parts of his project, but I do not think that he has drawn the correct inferences from his own research in other critical areas. We agree, for example, on the limited role of formal probability theory, and that proof at trial is largely comparative. However, the sustained argument that fuzzy logic and set theory provide a solution to the conjunction paradox, or for that matter much help at all on questions of fact, are simply wrong. ${ }^{33}$

29 This part is indebted to Ronald J. Allen \& Michael S. Pardo.

30 Like Professor Risinger, other recent writers are attempting to improve on the present situation. I believe this is true of Dale Nance, and what he terms an "interpretive" approach. Dale A. Nance, The Burdens of Proof: Discriminatory Power, Weight of Evidence, AND THE TENACITY OF BELIEF 11 (2016). I put these other efforts aside because of limited space here and because a systematic treatment is forthcoming from Allen \& Pardo.

31 Clermont, supra note 5.

32 This is true of Professor Nance as well. See, e.g., NANCE, supra note 30.

33 I should point out that in a series of emails in 2011, I put Professor Clermont on notice of the conceptual difficulties his proposal faced. Email from Ronald J. Allen, John Henry Wigmore Professor of Law, Northwestern Pritzker School of Law, to Professor Clermont, 
Professor Michael Pardo and I are working on a systematic treatment of relative plausibility and its critics, ${ }^{34}$ and this discussion complements the one that we will provide there.

I assume general awareness of fuzzy logic. In brief, it was created to give a means to handle linguistic vagueness in computer programming, and in that it was quite successful. It measures the extent to which a fact (John is five feet tall) "participates" in the (vague) set of "tall men." There can be more than one fuzzy set at play, and those sets can intersect, which is sometimes (but misleadingly) also referred to as the conjunction of the sets. The axiom of intersections of sets is that the "conjunction" of sets is equal to the lowest value of the sets involved. Professor Clermont presents a sustained argument that juridical proof should be analyzed as though it primarily involved fuzzy sets so that the "conjunction" of two elements is the smallest of the pertinent variables, and thus, although "it may sound like magic," 35 the conjunction paradox disappears.

The problem is that it does not for the reason that began this paper: the conjunction effect is a feature of the world, not of our logic or mathematics. It does not change as we embrace new or different ways of thinking. This is powerfully illustrated by a hypothetical that Professor Clermont gives that is designed to clinch the case for fuzzy logic, but it has exactly the opposite effect. According to Professor Clermont, the law "chooses" fuzzy logic over probability theory because it "behave[s] more appropriately than probabilities in a world filled with various kinds of uncertainty. ${ }^{36}$ Here is a last clever image to make the point as to what the law deals in:

Suppose you had been in the desert for a week without drink and you came upon two bottles marked $\mathrm{K}$ and $\mathrm{M}$ [and marked, respectively, with a .91 membership in the fuzzy set of potable liquids and a .91 probability of being a potable liquid]. Confronted with this pair of bottles, and given that you must drink from the one that you chose, which would you choose to drink from? Most people, when presented with this experiment, immediately see that while K could contain, say, swamp water, it would not ... contain liquids such as hydrochloric acid. That is, membership of 0.91 means that the contents of $\mathrm{K}$ are fairly similar to perfectly potable liquids .... On the other hand, the probability that $\mathrm{M}$ is potable "equals 0.91 " means that over a long run of experiments, the contents of $\mathrm{M}$ are expected to be potable in about

Robert D. Ziff Professor of Law, Cornell Law School (Dec. 27, 2011) (on file with author). I am now fleshing out the details of those points.

34 See Allen \& Pardo, supra note 5.

35 Clermont, supra note 5, at 15.

36 Clermont, supra note 8 , at 164-65. 
$91 \%$ of the trials. In the other $9 \%$ the contents will be deadlyabout 1 chance in 10 . Thus, most subjects will opt for a chance to drink swamp water. ${ }^{37}$

How does that map onto juridical proof? For there to be any mapping requires either that in the typical case the evidence presented has both forms of information, or alternatively that one can change the real world by changing one's commitments to various versions of set theory. Let me give my own "clever image" to demonstrate the problem. Suppose a Mr. Thomas Bayes, a good conventional probabilist, is lost in the desert and crawling in search of water. He comes across a Clermont bottle marked with "Water 0.91." He says to himself, "Oh, my God, there is a $9 \%$ chance that the bottle contains hydrochloric acid. If I drink it, I will die!" But, then he remembers that one class he had in Advance Probability Theory on fuzzy logic, and he says, "I swear allegiance to fuzzy logic, and therefore what is in the bottle participates in pure water to 0.91 , and thus it is perfectly safe to drink." Perhaps Professor Clermont disagrees, but I do not think this is how the world works. Mr. Bayes, like the legal system, knows what he knows, and that is the end of the matter. Maybe he knows (or believes, or whatever) that the bottle has a $91 \%$ chance of being water, and maybe he knows or believes it is $91 \%$ pure water, but whatever he knows will not change by switching mental gears lying there in the desert. Nor, hopefully we all agree, will the contents of the bottle change based upon his methodological commitments.

Now for a bit of the technical part. Professor Clermont either thinks that the world will change because of our changing commitments to various analytical techniques (in this case probability theory v. fuzzy logic) or that such a change in commitment brings about a change in our knowledge of the world, but his argument containts two fundamental mistakes of mathematical logic that demonstrate that no such unsettling and magical phenomena are at play. The first is that he has conflated (contorted, perhaps) the distinct ideas of probabilistic conjunction in mathematics and set intersection in set theory. ${ }^{38}$ The two ideas are just different, and there is no formalization that allows the one to be transposed into the other. ${ }^{39}$ A clue to this problem

37 Clermont, supra note 8, at 165-66 (quoting Bogdan R. Kosanovic, Fuzziness and Probability 2-3 (Feb. 8, 1995) (unpublished manuscript) (emphasis omitted)).

38 The contortion may stem from failing to keep distinct fuzzy logic, which employs the concepts of conjunction and disjunction, and fuzzy set theory, which employs the different concepts of intersection and union. For a discussion, see Jørgen Harmse, Continuous Fuzzy Conjunctions and Disjunctions, 4 IEEE TRANSACTIONS ON FuZZY Systems 295 (1996). Just as a heads-up, logic and math (including set theory) have a complicated relationship. ALFRED North WhiteheAd \& Bertrand Russell, Principia Mathematica (1910 and subsequent editions).

39 As I discuss below, a particular problem may involve both uncertainy and vaguenss, and a fuzzy probability is being developed to apply in such cases. However, this has nothing 
should have been evident from the foundations of set theory. Professor Clermont seems to think that "multivalent logic" has a different "rule" for intersection than bivalent logic that results in the radical difference in probabilistic conjunction. As he says, "one must use multivalent logic, including its rule that conjoined likelihood equals the likelihood of the least likely element." 40 So far as I can tell, he derives this proposition from an axiom (not a derivation) of fuzzy set theory, which is, as Clermont points out, the MIN operator. ${ }^{41}$ The intersection of two sets is defined as $\varphi \mathrm{A} \cap \mathrm{B}(\mathrm{x})$ $=\min (\varphi \mathrm{A}(\mathrm{x}), \varphi \mathrm{B}(\mathrm{x}))$, where " $\varphi$ " (phi) refers to the membership function that is necessary to define a fuzzy set. The clue that there are difficulties here is that the analogous axiom in classical set theory can be expressed in essentially identical terms except for the one referring to a crisp set and the other to a fuzzy set. One form of the definition of set intersection in crisp sets is $\mu \mathrm{A} \cap \mathrm{B}(\mathrm{x})=\min (\mu \mathrm{A}(\mathrm{x}), \mu \mathrm{B}(\mathrm{x}))$ where " $\mu$ " (mu) is the characteristic function of a classical set. ${ }^{42}$ Indeed, the general view, as Clermont notes, is that fuzzy set theory is a generalization of crisp set theory. Rather than there being some fundamental differences in this respect, one is simply a special case of the other. Rather obviously, the fact that classical set theory, like fuzzy set theory, defines the intersection of sets using the MIN rule does not warrant the conclusion that the probabilistic conjunction of two somewhat

to do with what Clermont is proposing.

40 CleRMONT, supra note 8.

41 As Clermont points out, Cohen's inductive logic has a similar rule. See Clermont, supra note 5 (citing L. Jonathan Cohen, The Probable And the Provable 89-91, 265-67 (1977)). His scheme, however, is quite idiosyncratic, and in addition the mathematics were never axiomatized. Thus it provides no support for Clermont's approach beyond another groundless assertion that the conjunction effect can be made to disappear. Belief functions, by contrast, allow statements about sets of propositions, which gets nearer to Clermont's ideas, but how they map onto the problem Clermont is addressing is unclear. In addition, they are quite controversial epistemically, because they often lead to obviously wrong results. See, e.g., Jean Dezert, Pei Wang \& Albena Tchamova, On The Validity of Dempster-Shafer Theory, 15th InT'L Conf. ON INFO. Fusion 655 (2012); Lotfi A. Zadeh, A Simple View of the Dempster-Shafer Theory of Evidence and its Implication for the Rule of Combination, 7 AI MAGAZINE 85 (1986). For a balanced review of belief functions that demonstrates their complexity done by a contractor of the United States Department of Energy, see KARL SENTZ \& Scott Ferson, Combination of Evidence in Dempster-Shafer Theory (2002), prod.sandia.gov/techlib/access-control.cgi/2002/020835.pdf. See also Special Issue: The Dempster-Shafer Theory of Evidence, 18 INT' J. INTELLIGENT SYS. 1 (2003).

42 For a discussion, see Thayer Watkins, Fuzzy Logic: The Logic of Fuzzy Sets, 6, http://www.sjsu.edu/faculty/watkins/fuzzysets.htm. See also Fuzzy Logic \& Fuzzy Sets from the Instituto Superior Técnico, https://fenix.tecnico.ulisboa.pt/downloadFile /3779578815313/CDI_SI_Fuzzy_Sets_2012.pdf. The formulation in the text is the logical equivalent of the standard formulation of set intersection. The difference is the standard formulation refers to the elements common to the sets whereas the logical equivalence refers to those elements that are not missing from each set. The reformulation makes the connection between fuzzy and crisp sets clearer. 
independent events is equal to the least likely of the events. ${ }^{43}$ Nor does it warrant that inference when dealing with fuzzy sets. As I said at the beginning of this paragraph, the two concepts are just different and cannot be transposed one into the other. ${ }^{44}$

The reason set theory defines intersection as it does is that it is a measure of the extent that sets have identical members rather than a measure of the probability within a defined probability space that one event or another will occur. To make this clear, consider the following diagrams of (1) the set of prime numbers between 1-10; (2) the set of prime numbers between $1-20$; and (3) the set of prime numbers between 1-100. Their intersection, or what Professor Clermont refers to as their conjunction, are the integers two, three, five, and seven. Now ask a different question. Suppose random draws are made from the set of integers $1-100$. What is the probability of a randomly drawn number being in one of the three original sets? It obviously varies from set to set. Professor Clermont simply conflates (contorts?) these two ideas.

43 In classic set theory the "min" rule identifies the elements that are members of both sets, whereas in fuzzy set theory the min rule identifies the extent to which a member participates in both sets and defines the intersection as the lower of the extent of participation in the two sets. Although these are different, fuzzy sets are generally thought to be generalizations of classic sets. See id. In both classic and fuzzy sets, intersection is one thing and conjunction is another. Clermont has simply conflated two different ideas. See text infra n. 43.

44 In addition to not accommodating the differing foundations and set theory, Clermont seems to have ignored the foundations of mathematics as well. At one point he suggests that "membership statements" within fuzzy logic can be meaningfully and easily multiplied to get comprehensible results. Clermont, supra note 8, at 175. Again, this is just wrong. The "numbers" in fuzzy logic are not precise equivalents to numbers on the number line. There is work being done now to define arithmetic operations on member statements, but these results bear no relationship to Professor Clermont's discussion. See, e.g., Yingxu Wang, On a Theory of Fuzzy Numbers and Fuzzy Arithmetic, in Advances In APPLIED AND Pure Mathematics 82 (Jerzy Balicki ed., 2014); Md. Yasin Ali, Abeda Sultana \& A F M Khodadad Khan, Comparison of Fuzzy Multiplication Operation on Triangular Fuzzy Number, 12 J. Mathematics 35 (2016); Ch.-Ch. Chou, The Canonical Representation of Multiplication Operation on Triangular Fuzzy Numbers, 45 COMPUTERS \& MATHEMATICS With APPLICATIONS 1601 (2003); Shang Gao \& Zaiyue Zhang, Multiplication Operation on Fuzzy Numbers, 4 J. SofTWARE 331 (2009). 
Figure 1.

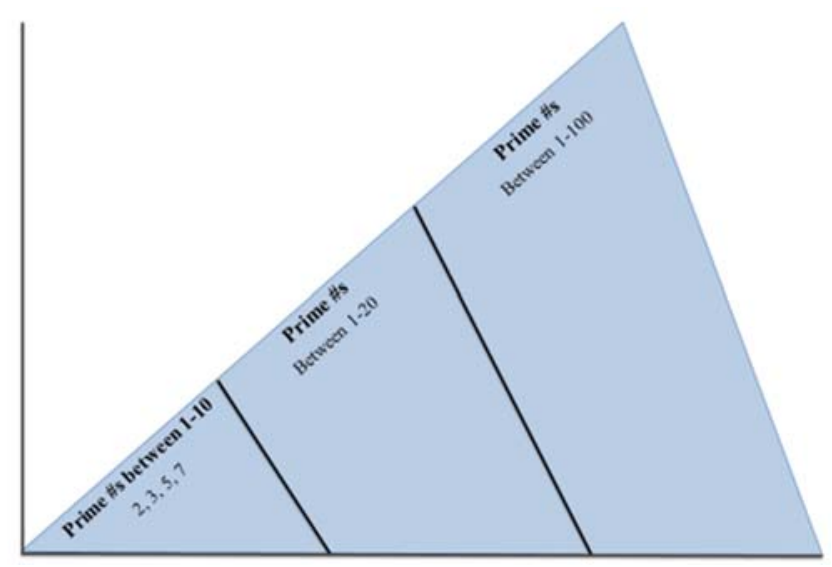

It is critical to see the point here, and it is made evident by reconsidering my "clever image" above of the hypothetical Thomas Bayes. Knowledge of uncertainty is simply different from knowledge of the extent of participation of an observation in a fuzzy set. The one cannot be transmuted into the other by fiat, which is what Professor Clermont purports to do. Correctly applying the logic of fuzzy sets, one can ask what is the intersection of the participation of each of these sets in "prime numbers" (admittedly not all that fuzzy of a concept, but remember that fuzzy sets are generalizations of crisp sets) and of course the answer is that which I gave above, which is the "MIN" value of 2, 3, 6, and 7. And, as I discuss below, this tells you little or nothing about any probabilistic question, such as the probability of drawing such a number in a random draw from the three sets.

There is actually a more serious problem with the analysis, and this is the second fundamental mistake of mathematical logic in Clermont's argument. It confuses membership statements with fuzzy sets, and in addition confuses fuzzy logic with fuzzy set theory. Professor Clermont gives the following example of what he thinks shows the implications of fuzzy set intersection, but it shows no such thing:

Begin with two membership statements ... [that] Tom is a .30 member of $\mathrm{A}[\mathrm{A}=$ tallness $]$ and a .40 member of $\mathrm{B}[\mathrm{B}=$ smartness $]$. Those numbers mean something like "Tom is not so tall" and "Tom is not so smart."

The fuzzy combination would yield: "Because Tom is not so tall and Tom is not so smart, Tom is not such a tall, smart man," 
[which] ... yields a .30 belief in that intersection. ${ }^{45}$

It is true, as noted above, that the intersection of fuzzy sets is defined as he describes, but the definition of set intersection does not extend to membership statements, which are not sets(at least not in Clermont's example; sets can have sets as members but this has nothing to do with his argument). Just as in crisp set theory and logic, the definition of set intersection is one thing, the definition for the logical operators "and" and "or" is another. Fuzzy set intersection has nothing to do with the likelihood of two elements being true. Rather: "In fuzzy sets, an element may partly belong to both sets with different memberships. A fuzzy intersection is the lower membership in both sets of each element." 46 In Clermont's example, on the basis of some observation, Tom may participate in one fuzzy set to .30 and in another fuzzy set on the same observation to .40 . The intersection of these two fuzzy sets on that variable would be the "MIN" value of .30. That is all there is to it.

The most peculiar aspect of this example is that, rather than having to appraise the likelihood that Tom is not so tall and not so smart (".30 belief in that intersection"), you know exactly how tall and smart Tom is. That is what generated the member statements in tallness and smartness in the first place. Whatever the membership function is, a certain height participates .30 in the fuzzy set of tallness and a certain intelligence participates .40 in the fuzzy set of smartness. The fuzziness is in the set, and not in the membership statement. That is probably why no person fluent in fuzzy set theory or logic, including the publications that he cites, ${ }^{47}$ embraces the thesis on offer, which I must confess looks like a "contortion" if ever there were one.

45 CleRMONT, supra note 8, at 175 .

46 Siti Zaiton Mohd Hashim, Fuzzy Logic \& Fuzzy Sets, at 32, https://comp.utm.my/sitizaiton/files/NotaSubjek/Nota\%20\%20AI\%20(1)/Fuzzy1.pdf.

47 For example, Clermont relies on Timothy J. Ross and W. Jerry Parkinson, who have this to say about membership statements and fuzzy sets:

Zadeh extended the notion of binary membership to accommodate various "degrees of membership" on the real continuous interval $[0,1]$ where the endpoints of 0 and 1 conform to no membership and full membership, respectively, just as the indicator function does for crisp sets, but where the infinite number of values in between the endpoints can represent various degrees of membership for an element $x$ in some set in the universe. The sets in the universe $X$ that can accommodate "degrees of membership" were termed by Zadeh as "fuzzy sets."

Timothy J. Ross and W. Jerry Parkinson, Fuzzy Set Theory, Fuzzy Logic, and Fuzzy Systems, in FuZzy Logic AND ProbabiLity ApPlications: Bridging the GAP 30 (Timothy J. Ross et al. eds., 2002). See Clermont, supra note 5, at 15-16 n.46. 
Indeed, quite at odds with the idea that one can just willy-nilly take the definition of the intersection of sets, apply it to membership statements, and, voila!, have a fuzzy theory of probability, those fluent in fuzzy set theory view the kind of example Clermont gives as a probabilistic problem. It is perfectly coherent to formally analyze the relationship between fuzziness and probability, and today there are people working in the field to develop a fuzzy probability theory. But that is not the hypothetical Clermont gives. There is no notion of probability at play; the notion at play is vagueness. You know Tom participates in the fuzzy sets of tallness and smartness and you know exactly the extent to which this is true.

For what it is worth, the contours of the emerging area of fuzzy probability are quite different from Professor Clermont's proposal, but they are exactly what one would predict. As Michael Beer describes these efforts:

Fuzzy probability theory is an extension of probability theory to dealing with mixed probabilistic/non-probabilistic uncertainty. It provides a theoretical basis to model uncertainty which is only partly characterized by randomness and defies a pure probabilistic modeling with certainty due to a lack of trustworthiness or precision of the data or a lack of pertinent information. ${ }^{48}$

He continues:

Fuzzy probability shares the common feature of all imprecise probability models: the uncertainty of an event is characterized with a set of possible measure values in terms of probability, or with bounds on probability. Its distinctive feature is that setvalued information, and hence the probability of associated events, is described with the aid of uncertain sets according to fuzzy set theory. This represents a marriage between fuzzy methods and probabilistics with fuzziness and randomness as special cases, which justifies the denotation as fuzzy randomness. Fuzzy probability theory enables a consideration of a fuzzy set of possible probabilistic models over the range of imprecision of the knowledge about the underlying randomness. The associated fuzzy probabilities provide weighted bounds on probability - the weights of which are obtained as the membership values of the fuzzy sets. ${ }^{49}$

48 Michael Beer, Fuzzy Probability Theory, in 6 ENCYCLOPEDIA OF COMPLEXITY AND Systems SCIENCE 4047, 4048 (Robert A. Meyers ed., 2009), https://doi.org/10.1007/978-0387-30440-3.

49 Id. at 3049. 
The progenitor of the field, Lotfi Zadeh, agrees. Fuzzy logic does not permit conventional probability to be dispensed with by wishing away probabilistic effects $^{50}$ :

Because it is possible that both uncertainty and imprecision can be present in the same problem, Zadeh (1995) has also claimed that "probability must be used in concert with fuzzy logic to enhance its effectiveness. In this perspective, probability theory and fuzzy logic are complementary rather than competitive." 51

There are hints throughout Clermont's complex discussion that he understands this, although there are stronger statements suggesting that his analysis somehow resolves or eliminates the conjunction paradox. ${ }^{52}$ On the one hand, if all he is saying is that there are typically both uncertainty and vagueness in legal decision-making, he would be right-_"common sense" if ever there were any. Perhaps handling the vagueness problem with some fuzzy set influenced methodology might be useful, but so far as I can tell, his work does not develop that idea, contenting itself with various claims of the advantages of fuzzy set theory as a substitute for probability theory. ${ }^{53}$ On the other hand, if he really believes that embracing fuzzy set theory actually eliminates the conjunction problem, he is simply wrong. It remains, being as I have said a number of times, a feature of the world and not our characterization of the world.

The examples that Professor Clermont gives of his proposal in action vividly highlight the contortions he is engaged in. He is right that vagueness is a problem for legal language, but it does not translate into the superiority of fuzzy set theory quite as he suggests. Repeatedly, Professor Clermont

50 Nozer D. Singpurwalla \& Jane M. Booker, Membership Functions and Probability Measures of Fuzzy Sets, 99 J. AM. StAT. Ass'N 867, 867 (2004) (quoting Lotfi A. Zadeh, Discussion: Probability Theory and Fuzzy Logic Are Complementary Rather Than Competitive, 37 TECHNOMETRICS, 271, 271-76 (1995)).

51 Id. And again, the work that Singpurwalla cites agrees with this as well. Ross \& Parkinson, supra note 47, at 29. Ross and Parkinson have this to say about fuzzy sets and probability: "To summarize, there is a clear distinction between fuzziness and randomness of an event. Fuzziness describes the ambiguity of an event, whereas randomness describes the likelihood of occurrence of the event." Id. at 31.

52 In a startling disregard of mathematics, Prof. Clermont says this about his hypothetical involving fault and identity: "While the MIN rule seems the obvious choice if identity is a matter of occurrence uncertainty and fault is a matter of imprecise vagueness, I think it should apply even if both factfinding percentages measure only random uncertainty." Clermont, supra note 8 , at 178 .

53 The decision theorist, David Schum, who has also an interest in legal evidence, explored precisely this relationship, reaching conclusions bearing no relationship to those of Professor Clermont. See, e.g., DAvid A. Schum, The Evidential Foundations of Probabilistic Reasoning 261-69 (1994). 
gives examples of how standard factual uncertainty intersects with legal vagueness, and implicitly suggests that his examples are paradigmatic cases of legal decision making. They are not, and the inference he draws from his examples is unjustified. Imagine, he says:

"a plaintiff trying to prove the identity of the perpetrator being Tom and also to prove the perpetrator being at fault. True, if the randomized odds are $60 \%$ and $70 \%$, the odds of Tom being at fault are $42 \%$. The product rule gives that result. But if the plaintiff has proved fault to $70 \%$, the odds on the remaining question of Tom being the perpetrator are $60 \%$. The MIN rule sets the likelihood of the conjunction at $60 \%{ }^{54}$

Like Clermont, I also approve of this result, but note why. The question of "fault" is a question of law: is what this person did within the meaning of "fault" for the purposes of the law? Perhaps an act that "participates" $70 \%$ in a certain concept of fault is at fault within the meaning of the law, but if so that simply means what the person did is within the legal definition no matter how it matches up to some idealized extreme version of the term. Once that decision is made, it is made for all time (or at least until an authoritative decision maker changes the outcome). Questions of "law" are indeed questions of "fact" but they have different consequences once the label is attached. So, if there really were any cases like this, Professor Clermont would be right but for the wrong reason. A legal conclusion is reached that what happened counts as fault, and now the only question is whether Tom is the perpetrator.

But in fact, there are no legal cases like this. "Fault" is not a free floating idea; with the possible exception of negligence, "fault" is composed of the sum total of what a person is alleged to have done. A person is at "fault" if he breaches a valid contract, but the factual elements of contract breach still have to be proven. A conclusion of "fault" might be reached in an intentional tort case after numerous facts about the event are decided, and so on. After those facts are decided, a conclusion must be drawn as to whether they are "breach" or "intentional tort," or whatever, but there again is the legal question lurking. In any event, many causes of action have multiple factual elements, a point I presume no one will dispute. ${ }^{55}$ Even if in each case there is legal vagueness, there remains factual uncertainty, and

54 Clermont approved of this result. Clermont, supra note 8, at 183.

55 Pick your favorite example. Mine has long been theft, which is the taking and carrying away of the personal property of another with the intent to deprive the owner permanently. Hopefully, it will not be contested that the typical cause of action comprises multiple elements. 
thus there remains the specter of probability theory. Returning to the main theme of this short paper, that uncertainty is a feature of the world and will not go away by applying the apparatus that may be useful for deciding vague "legal" questions to the different task of deciding factual questions. Mistakes will continue to accumulate as a function of mistakes on discrete factual elements, simple as that.

In his most recent discussion of the topic, Clermont notes that his analysis has "unfortunately convinced virtually no one," which for all the reasons above is not surprising. To his credit, he remains undeterred and doubles down on the analysis. Interestingly in doing so he digs his conceptual hole deeper but in a manner that points the way out of the morass. Clermont says:

Using the MIN rule yields the most accurate story, indeed, the story more likely than all the other possible stories combined. That is, the conjoined story is as likely as the weakest element, which has already satisfied the standard of proof if each element is more likely true than false. Moreover, the disjunction of the falsities that combines all other possible stories is only as likely as the most plausible of the falsities, which has already failed the standard of proof. ${ }^{56}$

This is obviously false. As patience is probably wearing thin, take a stylized example to make the point. Suppose a cause of action has six independent elements and there is a two-to-one chance of each being true. According to Clermont, no collection of stories could possibly be more likely than this. In fact, based on what you know and disregarding any ignorance and assuming independence, the probability of at least one other story being true is approximately $1-(2 / 3)^{5}=0.87$. Knowledge of uncertainty simply cannot be transmuted into the different problem of vagueness, which in turn will straighten everything out. For one last time, you know what you know with whatever implications it has.

Interestingly, Clermont would be right, and it would get him out of a host of difficulties, if the fact finder is comparing the explanations on offer and concludes that with respect to every element the plaintiff's overall explanation is superior to the defendant's - in other words, more or less the relative plausibility theory.

But wait! That sounds like comparing conjunctions. Now introduce the point that most proof at trial is massively overlapping, and the disagreements among explanations tend to focus on a limited set. In such circumstances, the logical problem of conjunctions is considerably

56 Clermont, supra note 5, at 18. 
diminished if not always entirely eliminated, and this is precisely how the legal system accommodates, domesticates, whatever, the burden of proof instructions, just as the relative plausibility theory explains. The instructions do focus the fact finder's attention on, in Professor Nance's words, the necessary elements that an explanation must possess in order for a plaintiff to win, ${ }^{57}$ and the overall proof process encourages, if not requires, the parties to advance competing explanations. This takes the probabilistic sting out of them. Generally speaking, the result is, as I say, more or less what the relative plausibility theory predicts. ${ }^{58}$ If Clermont would drop his fallacious argument about the magical qualities of multivalent logic and set theory, we would welcome him into our camp.

In any event, in my opinion, the fascination with burdens of proof played itself out. ${ }^{59}$ Explanations of juridical proof have to accommodate burden of proof instructions as they have to accommodate the reality of existence, but the compass of such explanations should be wider. When one looks more generally, one sees very commonsensical practical reasoning that, in the real world, has no choice but to compare alternative explanations of uncertain events using a host of different cognitive tools. The single-shot explanations of burdens of proof invariably miss the mark by failing to accommodate the complexity of the phenomenon under examination. That is precisely what the relative plausibility explanation is attempting to do, and why Professor Clermont is right that it has resisted the efforts of its critics to lay it to rest. I am also the person, however, who many years ago urged a young William Stuntz to get out of the field of constitutional criminal procedure because it kills brain cells. He rather tellingly proved me wrong by being a part of a young cohort of scholars who revitalized the field. Maybe what appears obvious to me now will likewise prove wrong. If so, I will be content to have been part of that sand in the oyster.

57 Dale A. Nance, A Comment on the Supposed Paradoxes of a Mathematical Interpretation of the Logic of Trials, 66 B.U. L. REV. 947, 948-52 (1986).

58 Out of perhaps an excess of caution, note that I say "more or less" in the text. It is obvious that the legal system does not require a comparison of each of the plaintiff's elements to each of the defendant'. Nonetheless, this would approximate what that legal system actually does in many cases because of the massive overlap of evidence. Clermont and others assert that a shortcoming of relative plausibility is that the "law" does not require defendants to offer a competing explanation. What they mean is that the instructions on the burden of proof do not so require, but much of the surrounding procedural context strongly encourages precisely that. In addition, the critics never address the likelihood of a defendant winning who has not produced a counter-explanation. In the rare case in which that happens, I predict convictions and holdings of liability will predominate, which casual empiricism confirms. Perhaps one source of apparent disagreement is differences in what various analysts are analyzing. Relative plausibility is not just an explanation of the instructions of burdens of persuasion, although it accommodates them reasonably well.

59 Even though I can't stop writing about them. My apologies again. 
To return, finally, to the question I was supposed to address, I have no good reason to think that fact finders are not doing a pretty good job at what we want them to do. Of course there are erroneous and peculiar outcomes, but there are massive numbers of cases and in any human institution things are going to go wrong. I suspect a bigger problem would be well-intentioned but fundamentally unjustified modifications of methods that turn out to have unintended consequences. Indeed, you might even think that captures a fair amount of the rules of evidence. My advice-were I forced to give itwould be to look for ways to enhance the practical reasoning of fact finders rather than obstruct it. A good example of this is the gradual evolution of the hearsay rule from a rule of exclusion to a rule of admission. ${ }^{60}$ A terrible example is the Crawford line of cases that retards reliable decision making for the flimsiest of reasons. ${ }^{61}$ It seems like the professionals - the judges, lawyers, and law professors - cannot stop trying to get fact finders to do what we want them to do, rather than letting them do their job.

60 Ronald J. Allen, The Hearsay Rule as a Rule of Admission Revisited, 84 FORDHAM L. REV. 1395 (2016).

61 Crawford v. Washington, 541 U.S. 36 (2004). For an example of the problems caused by Crawford, see Davis v. Washington, 547 U.S. 813 (2006) 